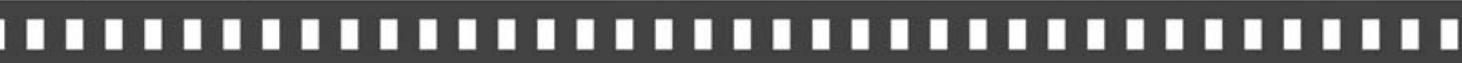 Da trajetória de um fotógrafo e da legibilidade da fotografia: esboço interpretativo sobre o trabalho de Claro Jansson

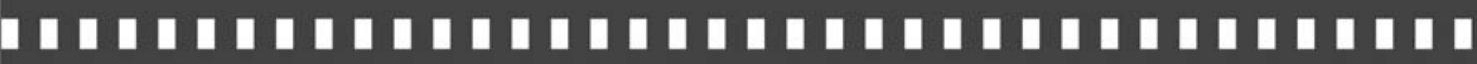

Ana Luisa Fayet Sallas

Rafael Ginane Bezerra 


\title{
Da trajetória de um fotógrafo e da legibilidade da fotografia: esboço interpretativo sobre o trabalho de Claro Jansson
}

\author{
On the trajectory of a photographer and the legibility of photography: \\ an interpretive sketch of the work of Claro Jansson
}

\author{
Ana Luisa Fayet Sallas * \\ Rafael Ginane Bezerra **
}

\begin{abstract}
Resumo: Tendo como pano de fundo a sociologia processual de Norbert Elias, este artigo discute a trajetória de Claro Jansson. Fotógrafo de origem sueca que viveu no Brasil entre 1891 e 1954, esse personagem é responsável por um extenso trabalho de documentação fotográfica. Registrou, entre outros temas marcantes, episódios relacionados à Guerra do Contestado e às atividades da Southern Brazil Lumber \& Colonization Company. A despeito da relevância desses registros, constata-se a predominância do seu uso como mera fonte ilustrativa. A partir da análise de parte de sua atividade epistolar pretende-se demonstrar que a trajetória do fotógrafo representa condição incontornável para conferir legibilidade às suas fotografias.
\end{abstract}

Palavras-chave: Claro Jansson, fotografia, trajetória, legibilidade.

\begin{abstract}
Taking as a background Norbert Elias' processual sociology, this article discusses the trajectory of Claro Jansson. A Swedish photographer who lived in Brazil between 1891 and 1954, this individual was responsible for an extensive work of photographic documentation. Among other important subjects, he registered episodes related to the Contestado War and the activities of the Southern Brazil Lumber \& Colonization Company. Despite the great relevance of these records, it is inferred that its use has been predominantly as a mere illustrative source. Through the analysis of part of his epistolary activity, the author intends to demonstrate that the photographer's trajectory is conditional upon attributing legibility to his photographs.
\end{abstract}

Key-words: Claro Jansson, photography, trajectory, legibility.

\footnotetext{
* Doutora. Professora do Programa de Pós-Graduação em Sociologia do Departamento de Ciências Sociais da Universidade Federal do Paraná.

** Doutorando do Programa de Pós-Graduação em Sociologia do Departamento de Ciências Sociais da Universidade Federal do Paraná.
} 


\section{Introdução}

Praticamente restrito ao simples uso ilustrativo até 2003, o rico acervo fotográfico produzido por Claro Jansson foi "redescoberto" na cidade de Itararé, interior de São Paulo, durante uma pesquisa sobre a estrada de ferro Sorocabana realizada pelo documentarista Vito D’Aléssio. Fruto de um feliz acaso, este reencontro com um extenso e variado conjunto de fotografias foi convertido num projeto que originou uma exposição, organizada no Museu da Imagem e do Som (MIS) da capital paulista, um livro, Claro Jansson: o fotógrafo viajante, e um pequeno documentário. (D’ALÉSSIO, 2003).

Esse projeto representou um marco para resgatar a importância do trabalho de Claro Jansson tanto para a história da fotografia no Brasil como para a memória visual de episódios marcantes da primeira metade do século XX. Como exemplo, basta dizer que são dele parte significativa das fotografias associadas à Guerra do Contestado, ocorrida entre 1912 e 1916, na região de litígio entre os estados do Paraná e de Santa Catarina, bem como as conhecidas fotografias de Getúlio Vargas a caminho da capital federal durante a Revolução de 1930 (Figuras 1 e 2).

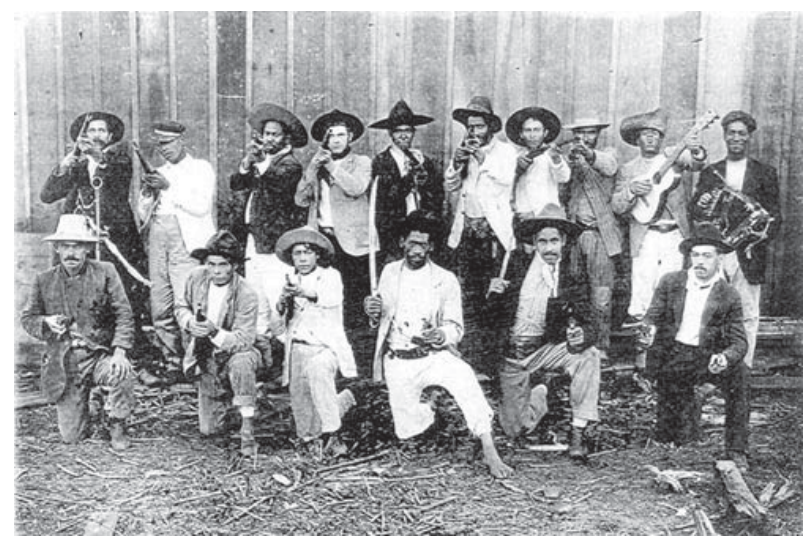

Figura 1 - Vaqueanos. Negativo de vidro / 9x12 cm 


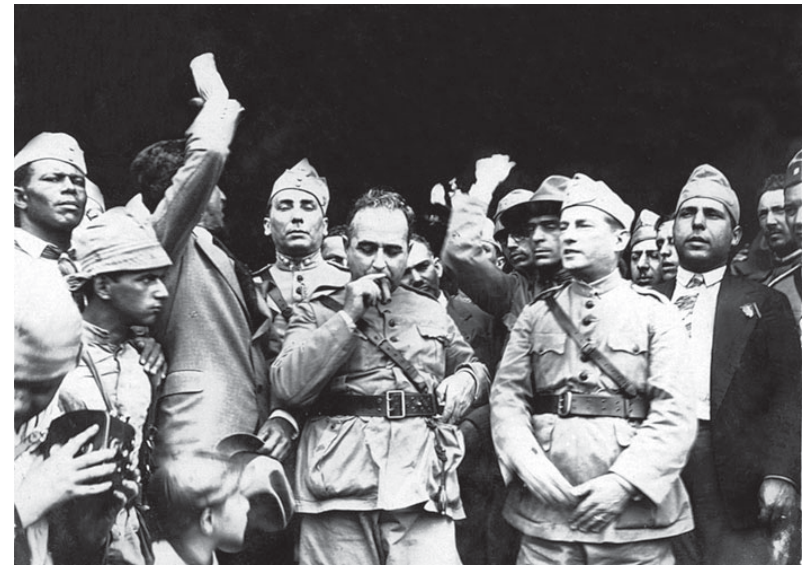

Figura 2 - Getúlio Vargas em Itararé. Negativo de vidro (estereoscópica) / 4x4,5cm)

Nesse contexto de "redescoberta", algumas tentativas de classificação do seu trabalho como fotógrafo foram esboçadas. Claro Jansson foi identificado como perito na prática da fotografia documental, como um dos pioneiros do fotojornalismo na região sul do país, como um profissional que guardou a tradição dos grandes fotógrafos viajantes e como um hábil comerciante de imagens.

Uma primeira análise do seu acervo revela, no entanto, que essas tentativas de classificação são inadequadas. Não se pode considerar a sua prática fotográfica, seja em termos de produto, método ou finalidade, como voltada para a imprensa ou regida pelo interesse jornalístico. De outro lado, a experiência pessoal que torna indissociável o objeto fotografado e aquilo que foi vivido pelo fotógrafo é incompatível com uma rígida dimensão documental. Da mesma forma, enquadrá-lo como um viajante, na medida em que este gênero de fotógrafo ficou marcado pela busca de imagens exóticas, sobrepuja o fato de que, predominantemente, Claro Jansson produziu imagens de temas que the eram, de alguma forma, familiares. Por fim, a extensão e a variedade de assuntos contidos em seu acervo são refratárias à prática de alguém que se distinguiu apenas pela habilidade em tratar a fotografia como um simples negócio. 
Mesmo quando tomadas de maneira combinada, essas formas de classificação não são adequadas para tornar mais legíveis as fotografias produzidas por Claro Jansson. O problema é que tais formas operam no registro de modelos estáticos e, tal como argumenta Elias (1995), são modelos incongruentes com o caráter processual dos dados sociais observáveis a que se referem. A legibilidade dessas fotografias demanda que sejam remetidas à dinâmica processual da trajetória do fotógrafo. Por conta disso, o objetivo do presente artigo consiste em elaborar um pequeno esboço interpretativo da trajetória de Claro Jansson.

Obviamente, uma trajetória que abrange praticamente meio século de atividade fotográfica não pode ser analisada de maneira exaustiva no espaço de um pequeno artigo. Portanto, cumpre ressaltar o efetivo caráter de esboço dos argumentos que seguem.

\section{Justificativa e abordagem}

Kossoy (2007) sugere que o resgate dos fotógrafos anônimos - ou praticamente desconhecidos - representa uma importante tarefa para quem estuda o campo da fotografia. Dado que os modelos tradicionais da história da fotografia tendem a repetir exaustivamente os mesmos nomes e imagens, proporcionar novos elementos para a reflexão acerca da expansão da prática fotográfica e de suas variadas aplicações é condição imprescindível para fazer avançar a compreensão sobre a memória histórica e fotográfica do país.

É nítida a influência do trabalho de Dubois (1993) sobre as proposições de Kossoy. Ao explorar os conceitos semióticos desenvolvidos por Charles Sanders Peirce, Dubois (1993) enfatiza a natureza indiciária da fotografia e inventaria as conseqüências que dela se desdobram. Ao contrário do ícone e do símbolo, a imagem indiciária é dotada de um valor singular que deriva de sua peculiar relação com o referente. Trata-se de um traço do real constituído a partir de um ato de 
corte. Ele ressalta que, para além do corte, tudo aquilo que o precede e o sucede está submetido a gestos culturais e codificados. Disso deriva a dimensão essencialmente pragmática da fotografia, o que significa dizer que as imagens fotográficas não têm sentido nelas mesmas. O seu sentido lhes é exterior.

Se a natureza indiciária da fotografia marca o seu vínculo com o real, esse vínculo é codificado pela atuação do fotógrafo, por suas escolhas técnicas, estéticas e ideológicas. Posteriormente, também será codificado pela possibilidade de diferentes aplicações, usos e recepções da fotografia. Logo, o tratamento metódico da imagem fotográfica sempre demanda um processo de decodificação que tem como uma de suas etapas a identificação da visão de mundo do próprio fotógrafo.

Não é questão fortuita, portanto, a preocupação de Kossoy (2007) em estimular o resgate de fotógrafos anônimos ou pouco conhecidos. Essa tarefa fundamenta a construção das condições de legibilidade para fotografias que fazem parte da memória histórica e que, usualmente, encontram-se apartadas do contexto que as originou.

Mas como identificar os vínculos de sentido entre o espaço social ocupado pelo fotógrafo e o registro visual elaborado a partir de uma determinada realidade? O presente artigo sugere que a noção de trajetória é de fundamental importância para que esta tarefa não seja executada através de pressupostos vagos. Se, por um lado, é válido postular que a visão de mundo do fotógrafo, suas escolhas técnicas, estéticas e ideológicas encontram-se, de alguma forma, refletidas na fotografia; por outro, é necessário reconhecer que o trabalho de investigação não se encerra aí. Afinal, visão de mundo e escolhas pessoais não são variáveis prontas e acabadas que se manifestam num simples ato de intencionalidade.

A esse respeito, a referência ao argumento de Bourdieu (1996, p.190) sobre a “ilusão biográfica” é incontornável. Nele, o autor fixa a trajetória como uma série de posições sucessivamente ocupadas num espaço sujeito a mudanças: 
Os acontecimentos biográficos se definem como colocações e deslocamentos no espaço social, isto é, mais precisamente nos diferentes estados sucessivos da estrutura da distribuição das diferentes espécies de capital que estão em jogo no campo considerado [...] o que equivale a dizer que não podemos compreender uma trajetória sem que tenhamos previamente construído os estados sucessivos do campo no qual ela se desenrolou e, logo, o conjunto das relações objetivas que uniram o agente considerado ao conjunto dos outros agentes envolvidos no mesmo campo e confrontados com o mesmo espaço dos possíveis.

Aqui, a negação da simples intencionalidade remete a noção de trajetória aos conceitos de campo e capital. Isso significa que a análise da trajetória de um fotógrafo em particular deve ser precedida pela construção dos estados sucessivos do campo fotográfico e pela identificação da posição que ele ocupou dentro dele.

Ocorre que, no caso específico da trajetória de Claro Jansson, as condições objetivas para a sua prática profissional não são caracterizadas pelos elementos que possibilitam a configuração de um campo fotográfico nos termos propostos por Bourdieu. Iniciando a sua carreira de fotógrafo como autodidata, vivendo sempre em pequenas cidades do interior do país, distante de querelas técnicas e estéticas sobre a fotografia, é impossível contextualizá-lo através de qualquer lógica que faça referência a disputas por legitimação e pelo reconhecimento do seu trabalho.

Há que se seguir outro caminho para reconstruir a trajetória de Claro Jansson e analisar o conteúdo do seu legado fotográfico. Esse caminho pode ser estabelecido a partir da sociologia processual de Elias (1995). Ao esboçar um ensaio de interpretação sociológica da vida de Mozart, ele pondera que a análise da vida de um indivíduo implica na compreensão dos anseios fundamentais que ele busca satisfazer. Ao contrário de predeterminados e estáticos, eles se modificam à medida que o indivíduo convive com outras pessoas ao longo da vida. Por outro lado, a satisfação desses mesmos anseios depende de uma constante negociação com o meio social em que o indivíduo vive. Portanto, a análise deve ser 
capaz de identificar o permanente contraponto entre os anseios individuais e o contexto social em que serão negociados pelo indivíduo. Elias (1995) ressalta que os homens vivem apenas através de figurações constituídas pelas relações de interdependência que estabelecem. Isso torna necessário identificar a posição do personagem em um dado espaço social como condição para apreender em que medida ele foi capaz ou não de concretizar os seus anseios.

A partir disso, o escopo da presente análise se delimita: identificar os anseios pessoais de Claro Jansson e as posições ocupadas por ele no espaço social em que foram negociados.

\section{Pequenas notas sobre a trajetória de um fotógrafo}

Claro Jansson, nascido na Suécia em 1877, chegou ao Brasil e se estabeleceu em Jaguariaíva, interior do Paraná, em 1891. Acompanhado do pai, da madrasta e quatro irmãos, separou-se de sua irmã mais velha, Ana Jansson, que permaneceu no país de origem. Com ela, manteve uma atividade epistolar que se estendeu até 1953. Através do conjunto de cartas produzido nessa atividade, é possível mapear os anseios individuais comentados anteriormente. O mais recorrente e significativo diz respeito ao seu desejo de provar aos seus familiares sua capacidade de construir a vida no Brasil por conta própria. Isso está refletido no fato de que, aos quatorze anos, abandonou a casa do pai e iniciou uma vida itinerante em busca do ganho da própria subsistência. Durante quinze anos, até esboçar as primeiras tentativas de estabelecer uma carreira como fotógrafo, viveu em vários lugares diferentes exercendo as mais variadas atividades.

Outro anseio peculiar é representado pelo medo de ser esquecido pelos familiares - particularmente a irmã - e conhecidos que permaneceram na Suécia. Suas cartas refletem uma verdadeira compulsão por descrever 
minuciosamente quem ele é, o tipo de vida que leva e aquilo que é capaz de realizar.

Identificados esses anseios fundamentais - obviamente insuficientes para esgotar a trajetória do personagem - resta a tarefa de caracterizar o espaço social no qual a sua trajetória se desenvolveu e as diferentes posições que ele ocupou. Para tanto, a sua atividade epistolar continua sendo fundamental.

Sabe-se que Jansson deixou a Suécia num momento em que o país atravessava grandes crises marcadas por confrontos entre sindicatos e governo. De acordo com Friborg (1998), ao contrário do que se pode supor, os imigrantes que saíram da Suécia neste período não fugiram da miséria absoluta. Antes, procuraram escapar do fantasma do desemprego. Por conta disso, e pelo fato de já possuírem um estilo de vida predominantemente urbano, buscaram restabelecer o mais rápido possível nos países de destino as atividades profissionais de origem. Foi assim que seu pai, André, oleiro de profissão, veio ao Brasil com o objetivo de iniciar as atividades de uma fábrica de telhas e tijolos.

Claro Jansson não chegou ao Brasil com um grupo de compatriotas imigrantes. Também não compôs, ao lado da família, um núcleo destinado à colonização. Sendo assim, que tipo de atividade, neste contexto, foi-lhe facultada para prover a própria subsistência? Em suas cartas, percebe-se que isto não foi tomado como um problema. Logo em sua primeira missiva à irmã, descreveu o Brasil como um lugar melhor do que a Suécia em todos os aspectos. Demonstrava acreditar que qualquer indivíduo capacitado para desenvolver algum trabalho envolvendo um mínimo de destreza manual teria asseguradas as condições para se manter. Acima de tudo, o seu depoimento indica que, para ele, era plena a idéia de que no Brasil seria possível obter algum tipo de mobilidade social através do próprio trabalho.

Essa possibilidade lhe cobrou, no entanto, uma contrapartida: o deslocamento constante por uma região em que novas oportunidades de trabalho surgiam como decorrência de um processo de modernização. De Jaguariaíva ele foi para a Lapa, ainda no Paraná. Depois foi para 
Porto União da Vitória, região que à época era objeto de litígio entre Santa Catarina e Paraná. De lá passou pelos campos de Palmas, na mesma região, rumando para a província argentina de Missiones. Tal percurso sugere que o processo de modernização mencionado estava vinculado à expansão da economia da erva-mate. Esse processo foi responsável pelo início da navegação de vapores no rio Iguaçu, pela abertura de estradas de rodagem, pela chegada de ferrovias e, acima de tudo, por uma reconfiguração na estrutura das relações sociais. Foi como um homem médio, ganhando a vida através de trabalhos típicos de artesão, que Claro Jansson experimentou os desdobramentos desse processo de modernização.

Progressivamente, por conta de sua vida itinerante, a satisfação dos seus dois anseios revelou-se problemática. Afinal, satisfez o anseio de se estabelecer por conta própria através do seu trabalho à medida que intensificou o distanciamento com seu grupo social de origem. Foi neste momento que a possibilidade de registrar fotograficamente as suas experiências apareceu em seu horizonte de escolhas. Não se trata, portanto, de um indivíduo que se interessou, pelo menos num primeiro momento, em converter a prática fotográfica em ganho ou profissão. Mesmo porque, como ele mesmo reconheceu em suas cartas, suas primeiras experiências como fotógrafo foram precárias. Entre outras limitações, suas fotografias refletiam a falta de habilidade para trabalhar a luz, o que resultava em imagens sub ou superexpostas.

A aproximação de Claro Jansson da prática fotográfica pode ser remetida ao argumento de Dubois (1993) a respeito da “pulsão fotográfica”. Dentro da lógica dessa pulsão, a prática fotográfica repousa essencialmente na relação originária com a situação referencial, pouco importando as suas qualidades plásticas ou miméticas. O que é decisivo é a sua capacidade de atestação. De fato, o que lhe motivava era a possibilidade de superar a distância através do testemunho visual.

Tendo iniciado suas atividades fotográficas em 1906, na província de Missiones, quando trabalhava com o comércio de erva-mate, não tardou, no entanto, a perceber a possibilidade de converter essa prática 
em trabalho. Tal como grande parte dos precursores da expansão da prática fotográfica no Brasil identificados por Kossoy (2002), Claro Jansson passou a combinar a atividade de fotógrafo com outros trabalhos.

Foi na já referida cidade de Porto União da Vitória que estabeleceu, por volta de 1910, o seu primeiro estúdio fotográfico. Dedicava-se aos retratos e à confecção de vistas da região, vendidas de forma avulsa ou organizadas em álbuns. Ele residia nessa cidade quando eclodiu o conflito que, posteriormente, ficou conhecido como Guerra do Contestado.

Jansson não foi o único a registrar fragmentos da Guerra do Contestado. No entanto, uma simples consulta aos principais títulos que tratam do tema indica que são suas as fotografias mais conhecidas, mesmo que predominantemente dissociadas de sua autoria. É fato que os conflitos, desde o surgimento da fotografia no século XIX, sempre representaram um tema fértil para os fotógrafos. Mas no caso de seu trabalho sobre o Contestado, o que prevalece como tema não é exatamente o conflito. Como um homem que estendeu a lógica do trabalho de artesão à prática fotográfica, não lhe coube produzir imagens a partir de escolhas meramente subjetivas. Ele rendeu os seus préstimos a quem estava disposto a documentar visualmente um discurso sobre o conflito: o exército.

\section{A Guerra do Contestado e a Southern Brazil \& Lumber Colonization Company}

Através de suas cartas, percebe-se que Claro Jansson escolheu Porto União da Vitória para fixar um estúdio fotográfico por conta da conjugação de dois fatores principais: os vínculos sociais já criados em sua passagem anterior pela cidade e a iminente conclusão de um trecho da ferrovia São Paulo - Rio Grande. Essa mesma ferrovia, que contribuiu para a formação de uma clientela capaz de tornar estável a sua nova atividade profissional, concorreu para precipitar os episódios que ampliaram o seu campo de atuação como fotógrafo. 
A respeito deste tema, a historiografia é farta. Sabe-se que a partir de 1906 a referida ferrovia passou a ser uma concessão da Brazil Railway Company, empresa comandada pelo empresário norteamericano Percival Farquhar. Criando também uma subsidiária para explorar a madeira e promover a colonização das terras marginais à ferrovia - a Southern Brazil Lumber \& Colonization Company - a Brazil Railway foi responsável por um violento processo de expropriação de terras. Eis um dos principais fatores associados à eclosão da Guerra do Contestado.

A discussão das causas, desdobramentos e interpretações a respeito desse episódio escapa aos limites desse artigo. Dois eventos pontuais, no entanto, demandam atenção para contextualizar a documentação fotográfica produzida por Claro Jansson.

Machado (2004) identifica uma correlação entre as expropriações promovidas pela Brazil Railwaye a formação de um grupo de sertanejos ao redor da figura messiânica do monge José Maria. Inicialmente localizado em Santa Catarina, esse grupo foi pressionado a se deslocar e acabou atravessando as fronteiras do Paraná. Ocorre que isso aconteceu justamente num momento em que os limites entre esses dois estados constituíam objeto de acalorado litígio. Assim, ao ser avisado sobre a entrada desse grupo naquilo que considerava seu território, o governo do Paraná enviou à região uma tropa do seu regimento de segurança comandada pelo Coronel João Gualberto Gomes de Sá. Este personagem é o objeto de uma das seqüências documentais produzidas por Claro Jansson sobre a Guerra do Contestado.

Por conta de suas pretensões políticas, era do interesse do Coronel João Gualberto a produção de um testemunho com o objetivo de enaltecer a sua missão. Ao desembarcar na estação ferroviária de Porto União da Vitória, rumo ao local conhecido como “campos do Irani”, onde deveria dispersar o grupo de “fanáticos”, ele se deparou com o fotógrafo que poderia concretizar esse objetivo. Das fotografias do conflito, selecionadas para a elaboração deste trabalho, oito têm como tema a campanha desse personagem. 
Ao contrário do que sugere o uso corriqueiro dessas fotografias, não se trata aqui de fotografia de guerra propriamente dita. Antes disso, trata-se da representação da estética do heroísmo personificado por um militar. Ao invés de instantâneos, as fotografias são encomendadas e, portanto, negociadas. Não é a câmera do fotógrafo que se desloca para encontrar o tema. É esse último que encena para aquela (Figuras 3 e 4).
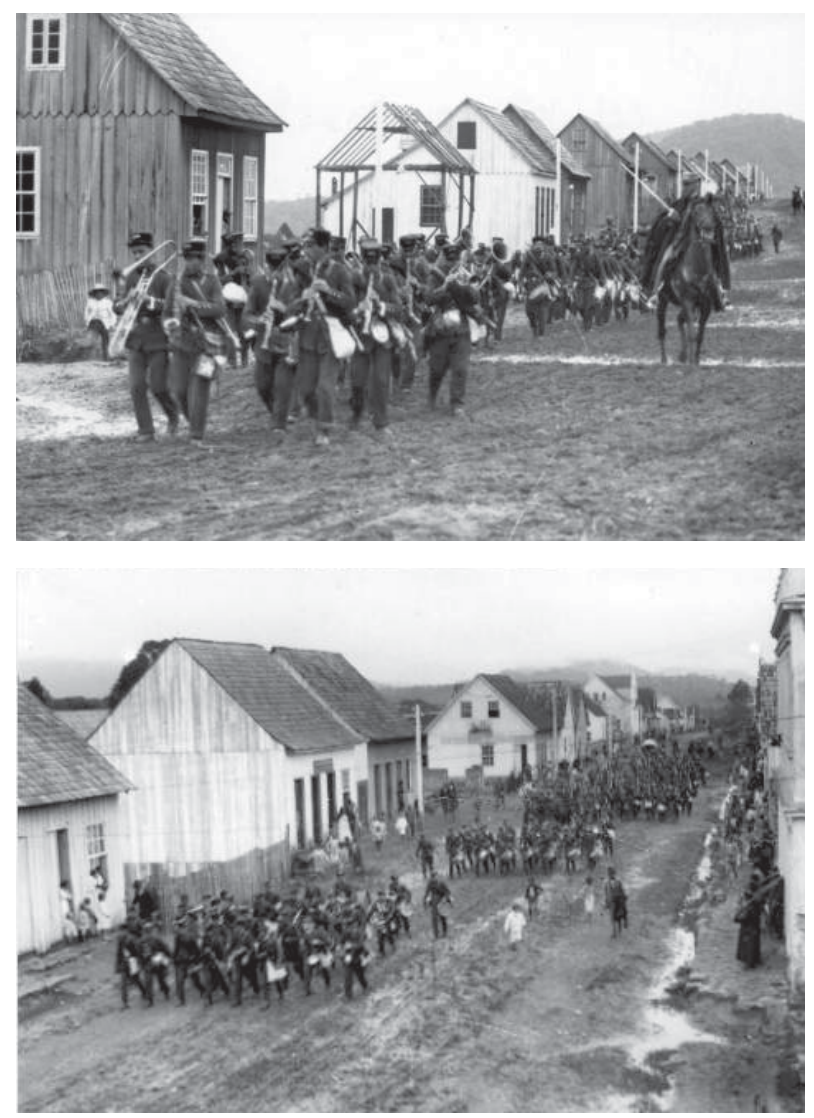

Figuras 3 e 4 - Coronel João Gualberto com as tropas da Força Pública do Paraná em Porto União da Vitória, 1912. Negativo de vidro / 9x12 cm) 
Sabe-se que o combate ocorrido nos “campos de Irani” foi da ordem da carnificina. Dele restaram mortos tanto João Gualberto como José Maria. Portanto, as fotografias anteriores (figuras 3 e 4) representam as últimas imagens do militar em vida. Da mesma forma, Jansson registrou as primeiras imagens do esquife que levou seu corpo para Curitiba (Figuras 5 e 6).
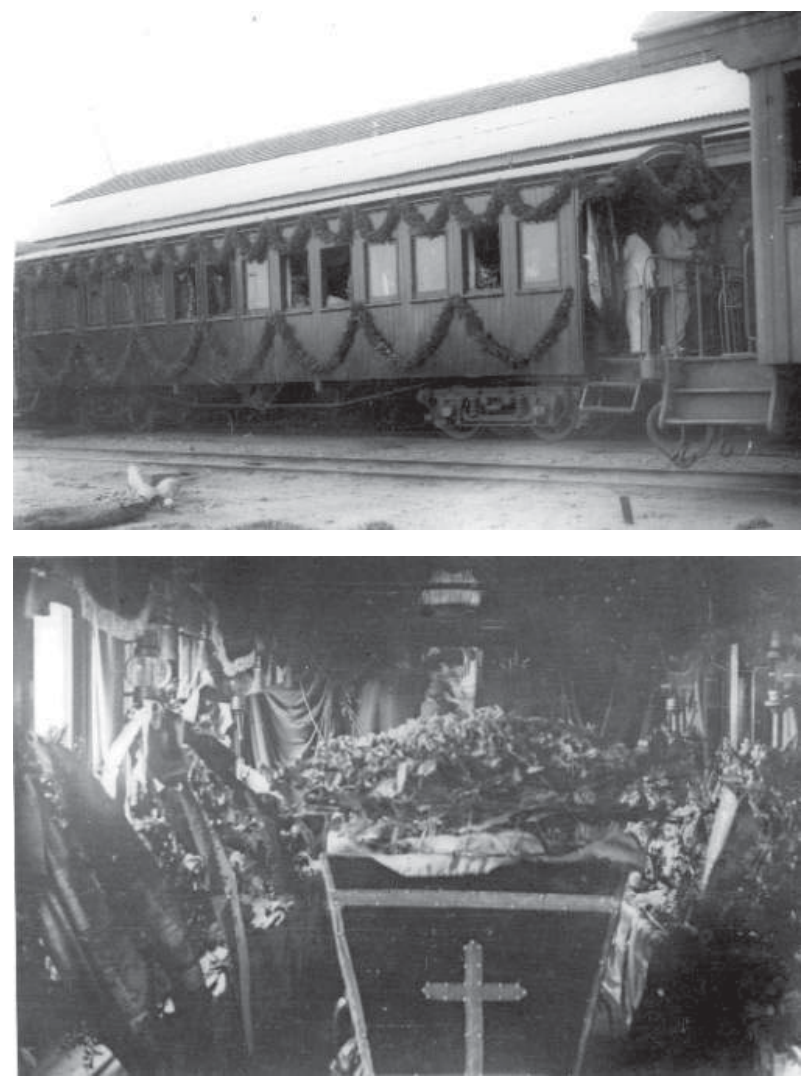

Figuras 5 e 6 - Vagão de trem com o esquife do Coronel João Gualberto na estação ferroviária de Porto União da Vitória, 1912. Negativo de vidro / 9x12 cm)

Neste caso, as fotografias cumpriram o papel que delas se esperava. Amplamente divulgadas na capital paranaense, em clima de comoção invulgar, elas concorreram para consagrar o militar pernambucano como um dos primeiros heróis paranaenses. 
Após a morte de João Gualberto, os conflitos relacionados ao Contestado aumentaram exponencialmente e sucessivas expedições militares foram derrotadas pelos sertanejos. Como uma segunda versão de Canudos, o movimento passou a ganhar repercussão na mesma medida em que desmoralizava o exército.

Reconhecendo sua incapacidade para restabelecer a ordem, os dois estados oficializaram um pedido de intervenção federal. Como resposta, em agosto de 1914, o então General Fernando Setembrino de Carvalho lançou a idéia de realizar uma efetiva campanha de guerra na região. Iniciava o segundo evento relevante para contextualizar a documentação fotográfica de Claro Jansson.

Como argumenta Rodrigues (2008), assim que estabeleceu o seu ponto de comando em Porto União da Vitória, o general não apenas reuniu as condições para colocar em prática a estratégia de guerra. Procurou também tomar as medidas necessárias para restituir a credibilidade do exército. Por conta disso, providenciou a elaboração de registros fotográficos para cobrir as operações. Esses registros foram posteriormente organizados num álbum com oitenta e sete imagens, parcialmente incluídas no relatório final de campanha elaborado por Setembrino de Carvalho.

Da mesma forma que as fotografias relacionadas a João Gualberto, as que documentam a campanha de Setembrino de Carvalho têm sido fartamente utilizadas como imagens da Guerra do Contestado. Paradoxalmente, servem tanto a publicações que comportam visões críticas em relação ao episódio como a outras que se alinham ao que poderia ser chamado de discurso oficial. Uma fatalidade do seu uso como mera ilustração: as imagens apenas acompanham, de forma muda, os sentidos que lhes são atribuídos pelo texto.

Novamente, depara-se com um caso de imagens negociadas. Sua autoria é de Claro Jansson. No entanto, seu trabalho é encomendado para produzir conscientemente um determinado discurso sobre o conflito. É assim que ao abrir o seu relatório, Carvalho (1916, p. 1) comenta: 
As fotografias que ilustram o presente relatório não foram aí incluídas para dar maior realce à exposição que ele encerra, senão precisamente com o fim de opor uma contra prova a acusações injustas assacadas contra o comandante das Forças em Operações no Contestado. O modo por que se apresenta a tropa em todos os serviços, perfeitamente fardada, equipada e convenientemente armada, como se verifica facilmente das fotografias, desmente de modo categórico a informação trazida à imprensa do Rio, de que os soldados andavam rotos e sem abrigo contra as intempéries. Elas representam também, juntamente com as instruções que seguem anexadas, documentos inestimáveis da organização dos abastecimentos, hospitais, etc., por onde se vê que o Exército entrou n'esta campanha com um aparelhamento perfeito, sendo tudo previsto e determinado em ordens preestabelecidas, na falta dos regulamentos essenciais a respeito.

Ou seja, as fotografias deveriam servir de testemunho para o discurso oficial, desautorizando, por conta da sua suposta objetividade, tudo aquilo dito em contrário. Neste caso, no entanto, mais do que a estética do heroísmo encarnado pelos militares, encontra-se uma estética que valoriza elementos sintomaticamente caros à modernidade, tais como organização, disciplina e tecnologia (Figuras 7, 8 e 9).

Como deve ter ficado evidente, há um intervalo de aproximadamente três anos entre as duas seqüências de documentação. Nesse interstício, a carreira de fotógrafo de Claro Jansson já estava consolidada, principalmente porque nesse período ele foi contratado para documentar as atividades da Brazilian Lumber \& Colonization Company. Estabelecida no município de Três Barras (SC), esta serraria é considerada uma das maiores que já funcionou em toda a América Latina. Mas de onde surgiu a motivação que origina este trabalho de documentação?

Uma pequena digressão é necessária para responder essa questão. A Lumber representava apenas um dos empreendimentos ligados ao imenso império de Percival Farquhar. Este empresário norteamericano iniciou suas atividades no Brasil em 1906, com o objetivo de construir uma ferrovia no complexo fluvial Madeira-Mamoré. Tal como afirma Gauld (2006), autor responsável por uma biografia de 

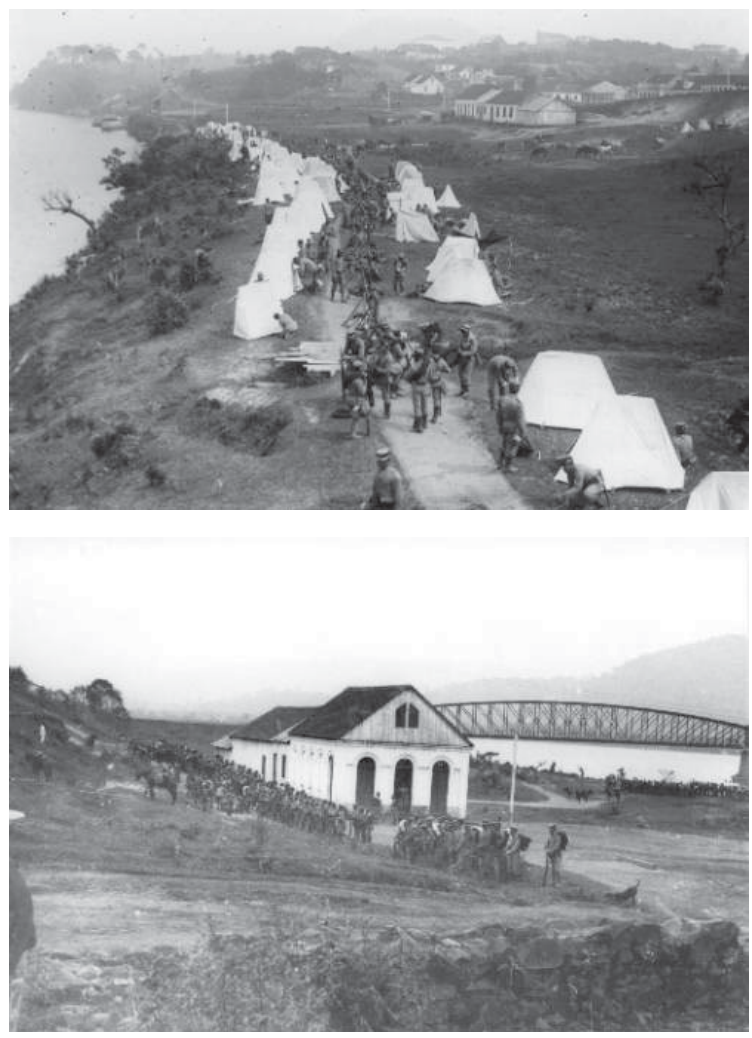

Figuras 7 e 8 - Acampamento do Exército em Porto União da Vitória às margens do Rio Iguaçu, 1915. Negativo de vidro / 9x12 cm

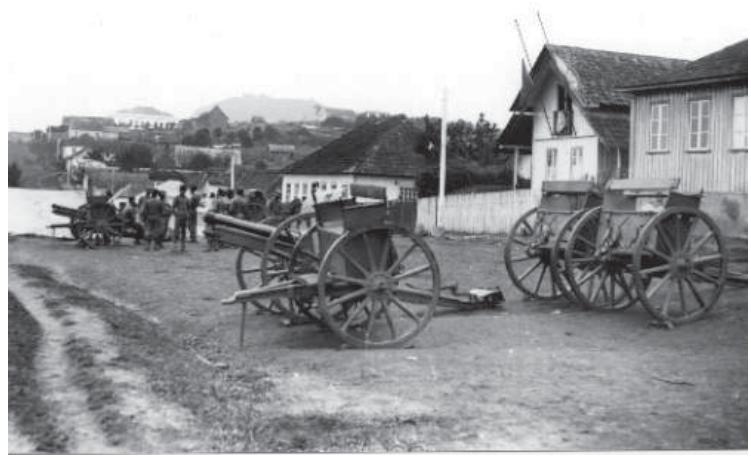

Figura 9 - Peças de artilharia do Exército em Porto União da Vitória, 1915.

Negativo de vidro $/ 9 \times 12 \mathrm{~cm}$ ) 
tipo hagiográfico sobre Farquhar, o empresário ambicionava concretizar uma obra considerada virtualmente impossível que lhe servisse como de cartão de visitas. Com isso, ele seria capaz de entrar nos mercados de capital mais afluentes, o que possibilitaria a viabilização de inúmeros outros empreendimentos.

Consciente do caráter épico da obra, contratou em Nova Iorque o fotógrafo Dana B. Merrill para documentar o seu andamento. Com os primeiros resultados, percebeu que poderia utilizar as fotografias para documentar a sua ousadia incomparável, para prestar contas aos financiadores que jamais veriam materialmente o próprio investimento e para contradizer as abundantes e generalizadas críticas que recebia. Fez da fotografia um componente de inventário ilustrado para o controle capitalista. Ao mesmo tempo, converteu-a em fiel testemunha de seu ímpeto modernizador.

Retomando a trajetória de Claro Jansson, agora é possível identificar a motivação que está na origem do seu trabalho fotográfico sobre a Lumber. Ele documentou os pinheirais expropriados pela empresa, o trabalho de derrubada de árvores, o seu transporte até o ponto de beneficiamento, os pátios para secagem de madeira, o cotidiano dos operários, as instalações físicas e toda a sorte de maquinaria que pôs o colosso em funcionamento. A seqüência de imagens sobre esse tema é vasta e não pode ser adequadamente trabalhada aqui. Por conta disto, apresenta-se apenas uma imagem singular com o objetivo de indicar a escala do assunto documentado (Figura 10).

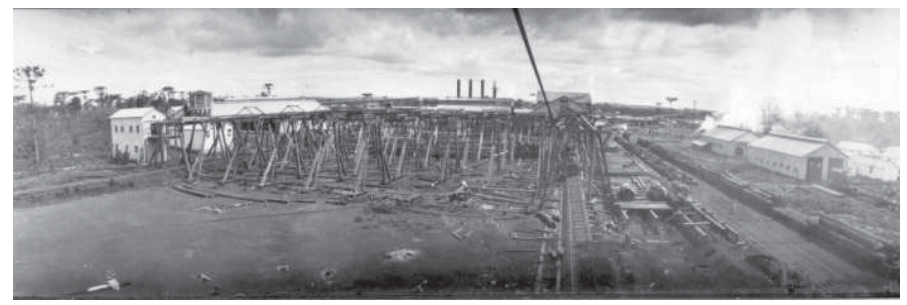

Figura 10 - Vista panorâmica da Lumber em Três Barras (SC), década de 1910. Negativo de vidro / 6x17,5 cm) 
É válido ressaltar que sua atuação como fotógrafo, nesse momento - associada, sem dúvida alguma, a outras habilidades - lhe rendeu um nítido processo de ascensão social. Não era mais um fotógrafo trabalhando como artesão, mas um personagem que compactuou com a perspectiva de transformação que a empresa introduziu na região. Os seus anseios já pareciam distantes daqueles iniciais. Desejava estabelecer definitivamente um padrão de vida urbano e isso lhe foi proporcionado pelas relações sociais que estabeleceu a partir da Lumber.

Sucede que, como qualquer empreendimento de natureza extrativista intensiva, num intervalo relativamente curto de tempo, a Lumber foi obrigada a deslocar progressivamente as suas atividades para outra região. Acompanhando esse deslocamento, Jansson passou a documentar as atividades da empresa num local chamado Fazenda Morungava, próximo a Itararé. No final da década de 20, estabeleceu residência definitiva, até 1954, nesta cidade de divisa entre Paraná e São Paulo.

Em carta à irmã, registrou que, embora não fosse mais um homem novo, ainda tinha saúde e muita disposição. Como se resgatasse um tema esquecido, ponderou que, apesar de ser obrigado a trabalhar muito, era possível levar uma boa vida no Brasil através da atividade de fotógrafo. Ao mesmo tempo, fez as primeiras referências aos filhos já crescidos que, de alguma forma estavam com a "vida encaminhada". O que lhe restava? Pois eis que em 1930, a pacata cidade de Itararé foi transformada no palco de uma famosa "batalha que não houve". Tropas do governo federal, enviadas por Washington Luís, e as forças revolucionárias que vinham do sul, sob o comando de Getúlio Vargas, posicionaram-se em pontos estratégicos da estrada de ferro Sorocabana. Ora, coube a ele registrar o momento em que Vargas, ao discursar para os seus correligionários na estação ferroviária de Itararé, foi aclamado o novo presidente da República (Figura 11). 


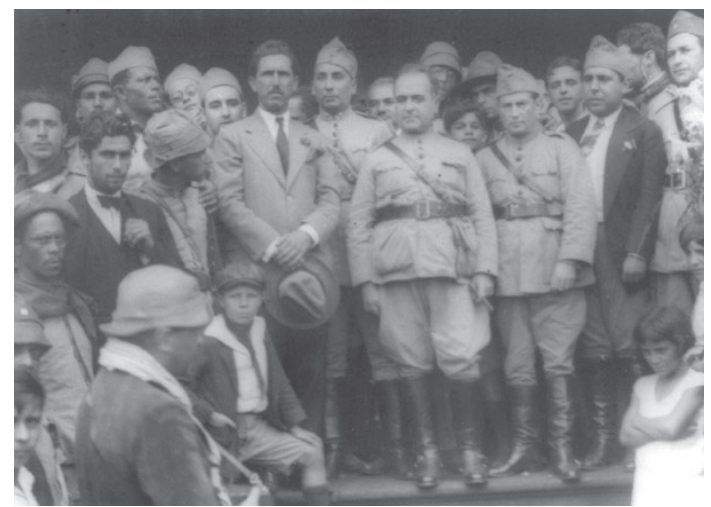

Figura 11 - Getúlio Vargas na estação ferroviária de Itararé durante a Revolução de 1930. Negativo de vidro - Estereoscópica / 4x4,5 cm)

Tomada de maneira isolada, a realização dessa fotografia - que na verdade compõe uma série ao lado de outras que registram o movimento de tropas e lideranças políticas em passagem pela Sorocabana - pode sugerir a interferência de algum acaso. Não se deve esquecer, no entanto, que o fotógrafo que a realizou já possuía, naquele momento, uma longa trajetória. E qual seria o vínculo entre o conjunto de fotografias relacionadas à Revolução de 1930 e a trajetória de Claro Jansson? De maneira bastante simplificada, seria possível apontar que a demanda dos periódicos por fotografias sobre o tema combinada à sua posição peculiar implicou em uma nova configuração para a sua prática fotográfica. O mesmo pode ser dito sobre as suas fotografias relacionadas à Revolução Constitucionalista de 1932.

A atividade fotográfica de Claro Jansson avançou até 1954, ano de sua morte. Há, portanto, mais duas décadas inteiras da trajetória desse fotógrafo para analisar. Seria inadequado supor que seus registros sobre a Constitucionalista representam o seu último trabalho de destaque. Excetuando as abundantes fotografias de estúdio e aquelas restritas ao cotidiano de Itararé, seria possível chamar a atenção, por exemplo, para os registros de futebol - que envolvem 
imagens da Copa do Mundo de 1950 - e de viagens - Buenos Aires e Montevidéu. Muitos outros temas por ele fotografados ficaram de fora dessas rápidas notas. No entanto, como foi salientado ainda na introdução, o que se apresentou aqui foi um esboço. Não existe a pretensão irreal de se esquadrinhar meio século de fotografia através de um único artigo.

\section{Considerações Finais}

É pertinente afirmar que a trajetória de Claro Jansson acompanhou e refletiu o extenso processo de modernização que caracterizou parte da região sul do Brasil nas primeiras décadas do século XX num duplo sentido. De um lado, foi marcada pelos dedobramentos desse processo que incidiram sobre o seu próprio horizonte de escolhas e sobre a formulação / negociação dos seus anseios individuais. De outro, converteu algumas de suas manifestações, tais como os episódios relacionados ao Contestado e ao funcnioamento da Lumber, em imagens fotográficas.

Essas imagens têm sido usualmente utilizadas com função ilustrativa, oferecendo um simples suporte visual para informações levantadas a partir de outras fontes. Trata-se de uma aplicação muito limitada para um corpo documental extremamente valioso, que encerra muitas possibilidades de investigação. A abordagem adotada na elaboração da pesquisa, que tem como resultado parcial o presente artigo, partiu do pressuposto de que a análise da trajetória de Claro Jansson oferece ganhos analíticos decisivos para a interpretação e valoração de suas fotografias. O trabalho mais detido com o conjunto dessas fotografias demanda, no entanto, o esforço de outros pesquisadores e de muitos outros artigos. 


\section{Referências}

BOURDIEU, Pierre. A ilusão biográfica. In: FERREIRA, Marieta de Moraes; AMADO, Janaína. Usos e abusos da história oral. Rio de Janeiro: FGV, 1996. p.183-191.

CARVAHO, Fernando Setembrino de. Relatório apresentado ao general de divisão José Caetano de Faria, Ministro da Guerra. Rio de Janeiro: Imprensa Militar, 1916.

D’ALÉSSIO, Vito. Claro Jansson: o fotógrafo viajante. São Paulo: Dialeto, 2003.

DUBOIS, Phillipe. $O$ ato fotográfico e outros ensaios. 10.ed. Campinas: Papirus, 1993.

ELIAS, Norbert. Mozart: sociologia de um gênio. Rio de Janeiro: Zahar, 1995.

FRIBORG Goram. Brasilien Svenskarna-Utvandring, Invandring, Bosattning (1850-1940). Mímeo.

GAULD, Charles A. Farquhar o último titã: um empreendedor americano na América Latina. São Paulo: Cultura, 2006.

KOSSOY, Boris. Dicionário histórico-fotográfico brasileiro: fotógrafos e ofício da fotografia no Brasil (1833-1910). São Paulo: Instituto Moreira Sales, 2002.

. Os tempos da fotografia: o efêmero e o perpétuo. Cotia:

Ateliê Editorial, 2007.

MACHADO, Paulo Pinheiro. Liderança do Contestado. Campinas: Unicamp, 2004.

RODRIGUES, Rogério Rosa. Das ordens à disciplina. In: ESPIG, Márcia Janete; MACHADO, Paulo Pinheiro (Org.). A Guerra Santa revisitada: novos estudos sobre o movimento do Contestado. Florianópolis: UFSC, 2008. p.13-32. 